\title{
The effects of plant cysteine proteinases on the nematode cuticle
}

\author{
Victor S. Njom ${ }^{1,2}$, Tim Winks ${ }^{1,3}$, Oumu Diallo ${ }^{1,3}$, Ann Lowe ${ }^{4}$, Jerzy Behnke ${ }^{4}$, Mark J. Dickman ${ }^{5}$, lan Duce ${ }^{4}$, \\ lain Johnstone $e^{6}$ and David J. Buttle ${ }^{1 *}$
}

\begin{abstract}
Background: Plant-derived cysteine proteinases of the papain family (CPs) attack nematodes by digesting the cuticle, leading to rupture and death of the worm. The nematode cuticle is composed of collagens and cuticlins, but the specific molecular target(s) for the proteinases have yet to be identified.

Methods: This study followed the course of nematode cuticle disruption using immunohistochemistry, scanning electron microscopy and proteomics, using a free-living nematode, Caenorhabditis elegans and the murine GI nematode Heligmosomoides bakeri (H. polygyrus) as target organisms.
\end{abstract}

Results: Immunohistochemistry indicated that DPY-7 collagen is a target for CPs on the cuticle of C. elegans. The time course of loss of DPY-7 from the cuticle allowed us to use it to visualise the process of cuticle disruption. There was a marked difference in the time course of damage to the cuticles of the two species of nematode, with $\mathrm{H}$. bakeri being more rapidly hydrolysed. In general, the CPs' mode of attack on the nematode cuticle was by degrading the structural proteins, leading to loss of integrity of the cuticle, and finally death of the nematode. Proteomic analysis failed conclusively to identify structural targets for CPs, but preliminary data suggested that COL-87 and CUT-19 may be important targets for the CPs, the digestion of which may contribute to cuticle disruption and death of the worm. Cuticle globin was also identified as a cuticular target. The presence of more than one target protein may slow the development of resistance against this new class of anthelmintic.

Conclusions: Scanning electron microscopy and immunohistochemistry allowed the process of disruption of the cuticle to be followed with time. Cuticle collagens and cuticlins are molecular targets for plant cysteine proteinases. However, the presence of tyrosine cross-links in nematode cuticle proteins seriously impeded protein identification by proteomic analyses. Multiple cuticle targets exist, probably making resistance to this new anthelmintic slow to develop.

Keywords: C. elegans, H. bakeri, Papain, Papaya latex, Cuticle, Anthelmintic, Proteomics, Imaging, Immunohistochemistry

\footnotetext{
*Correspondence: d.j.buttle@sheffield.ac.uk

1 Department of Infection, Immunity and Cardiovascular Disease, The University of Sheffield Medical School, Beech Hill Road, Sheffield S10 2RX, UK

Full list of author information is available at the end of the article
}

\begin{abstract}
Background
Parasitic nematodes cause enormous public health, agricultural and economic problems worldwide, as pathogens of humans [1, 2], livestock [3] and crops [4]. In humans, treatment of gastrointestinal (GI) nematode/soil-transmitted helminth (STH) infections is usually with one or a combination of two or all three common classes of synthetic anthelmintics: benzimidazoles, nicotinic acetylcholine agonists and macrocyclic lactones [5], whose
\end{abstract}

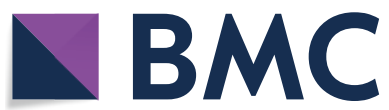

(c) The Author(s) 2021. This article is licensed under a Creative Commons Attribution 4.0 International License, which permits use, sharing, adaptation, distribution and reproduction in any medium or format, as long as you give appropriate credit to the original author(s) and the source, provide a link to the Creative Commons licence, and indicate if changes were made. The images or other third party material in this article are included in the article's Creative Commons licence, unless indicated otherwise in a credit line to the material. If material is not included in the article's Creative Commons licence and your intended use is not permitted by statutory regulation or exceeds the permitted use, you will need to obtain permission directly from the copyright holder. To view a copy of this licence, visit http://creativeco mmons.org/licenses/by/4.0/. The Creative Commons Public Domain Dedication waiver (http://creativecommons.org/publicdomain/ zero/1.0/) applies to the data made available in this article, unless otherwise stated in a credit line to the data. 
modes of action range from binding to microtubules and blockage of metabolic pathways to effects on neuromuscular transmission [6]. The intensive use of drugs and the dependence of treatment of nematode infection on only a few drugs with similar modes of action have put pressure on the drug candidates with resulting loss of potency due to development of resistance by target nematodes [7-9]. Nematode resistance to anthelmintics is a crisis in certain livestock industries, particularly in small ruminant animals, where triple-resistant nematodes have been reported [10]. Though the greatest problem is in treatment of ruminants, there are signs that resistance is also developing in human populations $[7,8,11,12]$.

Nematodes are protected from their environment by their cuticle, which also confers shape and integrity to the worms. The cuticle is made of two important structural protein types, collagens and cuticlins, encoded by about 160 and at least 8 genes, respectively, in C. elegans. These structural proteins are strengthened by the presence of disulphide and tyrosine-based cross-links [13-15]. The parasitic nematode species that inhabit the gastrointestinal tract produce proteinase inhibitors of serine proteinases and pepsin, and hence are able to avoid being digested and can survive in the gut lumen [16-18]. However, in the GI tract they are not exposed to high concentrations of cysteine proteinases (CPs) and therefore do not experience selective pressure to develop inhibitors to this class of proteinase in order to survive in the gut. Their protective cuticle may therefore be sensitive to digestion by this class of proteinases. Tropical countries have relied to some extent on plant extracts for the treatment of nematode infections [19], including extracts that contain CPs [20-22].

Many plant CPs are in the papain family (subfamily $\mathrm{C} 1 \mathrm{~A}$ in the phylogenetic classification in the MEROPS database-http://merops.sanger.ac.uk/) [23]. They attack the nematode cuticle, weakening its structure sufficiently to allow the internal high hydrostatic pressure in the pseudocoelomic cavity to rupture the cuticle, resulting in evisceration and death of the worm. This mode of action appears to be the same both in vitro and in vivo [24-27]. Free-living and plant parasitic nematodes undergo the same fate as animal GI nematodes [28-30].

To accomplish growth, the cuticle is shed five times during the life of a nematode in a process known as moulting or ecdysis [15]. This involves the digestion of the old cuticle by cysteine and metalloproteinases [15, 31]. It is possible that the anthelmintic action of plant CPs may therefore mimic the process of removal of the old unwanted cuticle during moulting.

For CPs to be accepted as an anthelmintic for livestock or for human use, we need to understand more about the mode of action, safety and toxicity. We have therefore investigated cuticle disruption by CPs of a well-annotated free-living nematode, C. elegans, using an immunohistochemical approach, then described the time-dependent process of cuticle digestion of C. elegans and a murine GI nematode, Heligmosomoides bakeri, using scanning electron microscopy and immunohistochemistry. We also undertook a proteomic approach in an attempt to identify the molecular targets for CPs. The presence of multiple targets for CPs in the cuticle is highly likely to decrease the chance of future resistance developing against the drug.

\section{Methods \\ C. elegans culture}

The C. elegans genome contains two cystatins, the functions of which include the inhibition of papain-like CPs [29]. The following C. elegans strains were used in this study: Bristol N2 wild type (WT), the cystatin gene null mutant RB1207 cpi-2(ok1256) [29] and cuticle collagen gene mutant dpy-7(qm63) [32]. We used a slight modification of the protocol described by Stiernagle in www. wormbook.org [13]. The C. elegans strains were cultured on plates of nematode growth medium (NGM) agar spread with an Escherichia coli (OP50) lawn. Worms from each plate were washed with approximately $10 \mathrm{ml}$ of ice-cold M9 buffer into $50 \mathrm{ml}$ sterile centrifuge tubes. The worms were settled on ice for $15 \mathrm{~min}$, and the supernatant containing food bacteria was removed with a Pasteur pipette, leaving the worm suspension. Twenty millilitres of $60 \%(\mathrm{w} / \mathrm{v})$ sucrose was added to the tube and mixed by inversion then centrifuged at $121 \times g$ for $2 \mathrm{~min}$. Ten millilitres of this suspension containing the worms was aspirated into a new tube and washed twice with ice-cold M9 by centrifuging at $121 \times g$ for $2 \mathrm{~min}$. The agar debris and bacterial sediments at the bottom of the tube were discarded. Worms were aliquoted in volumes of $1 \mathrm{ml}$ ( 4500 worms) and stored at $-20^{\circ} \mathrm{C}$ until use. To obtain a synchronised population, we used a modification of the protocol described by Stiernagle in www.wormbook.org [13], and adult worms were washed off the plates with $\mathrm{K}$ medium (prepared as $53 \mathrm{mM} \mathrm{NaCl}, 32 \mathrm{mM} \mathrm{KCl}$ ). The worm suspension was passed through a $5 \mu \mathrm{m}$ microplate sieve to remove any L1 and L2 larval stages. The resulting suspension was centrifuged at $755 \times g$ for $30 \mathrm{~min}$. The supernatant was removed from the tube without disturbing the worms and replaced with egg isolation bleach $(1 \%$ sodium hypochlorite and $0.5 \% \mathrm{KOH}$ ). The tubes were shaken for $7 \mathrm{~min}$ to disrupt the worms and release their eggs, then the tube was centrifuged for $3 \mathrm{~min}$ at $755 \times g$. The supernatant was replaced with fresh $\mathrm{K}$ medium, and the process was repeated three times to remove any trace of the bleach solution. The tube was shaken on a rotary shaker overnight to allow L1 to hatch. The contents of 
the tube were then allowed to settle, and the supernatant was removed, leaving $2 \mathrm{ml}$ in the $50 \mathrm{ml}$ tube, which was transferred to several NGM agar plates with the aid of a pipette and incubated at $15{ }^{\circ} \mathrm{C}$ for $24,39,55,74$ or $95 \mathrm{~h}$ to obtain L2, L2-L3, L3-L4, L4 and adult worms, respectively. All experiments on C. elegans described in this paper were undertaken using worms harvested after $95 \mathrm{~h}$.

\section{Heligmosomoides bakeri culture}

We used the method described by Behnke and Harris [33]. Briefly, oral gavage with a blunt-ended needle was used to infect 7-week-old BKW mice with L3 of $\mathrm{H}$. bakeri (Home Office Licence 40/3138) [34]. The mice were housed and maintained at the University of Nottingham, BioSupport Unit. Mice were provided with water and food ad libitum. At least 2 weeks post-infection, the mice were sacrificed by asphyxiation with $\mathrm{CO}_{2}$ and dissected. The intestine was carefully removed and placed inside a $15 \mathrm{~cm}$-diameter Petri dish containing pre-warmed $\left(37^{\circ} \mathrm{C}\right)$ Hanks' balanced salt solution (HBSS). To quicken the emergence of the adult worms from the mouse intestinal lumen, the intestine was carefully slit open longitudinally and incubated in HBSS or suspended in gauze in HBSS in a $50 \mathrm{ml}$ beaker kept in a $37^{\circ} \mathrm{C}$ water bath. Worms collecting in the bottom of the beaker were tipped into a Petri dish, and with the aid of a stereomicroscope, adult worms that had migrated out of the gut lumen were pipetted or picked up with the aid of fine forceps and transferred into another Petri dish containing HBSS. Worms were later separated into males and females, and aliquots were stored in $2 \mathrm{ml}$ mini-fuge tubes at $-20^{\circ} \mathrm{C}$.

\section{Preparation of worm cuticles}

We used a modification of the method described by Cox et al. [35]. An aliquot of either C. elegans strains or $H$. bakeri (containing $\sim 4500$ C. elegans or $\sim 120 \mathrm{H}$ bakeri adult worms) in a $1.5 \mathrm{ml}$ mini-fuge tube was thawed, and $1 \mathrm{ml}$ of $\mathrm{H}_{2} \mathrm{O}$ was added and vortexed to mix. The minifuge tube was centrifuged, and the water was decanted. Following phosphate-buffered saline (PBS) washes, $1 \mathrm{ml}$ of $1 \%(\mathrm{w} / \mathrm{v})$ sodium dodecyl sulphate (SDS) in $0.125 \mathrm{M}$ Tris- $\mathrm{HCl}(\mathrm{pH}$ 6.8) was added to the pellet, boiled for $5 \mathrm{~min}$, incubated at ambient temperature for $1 \mathrm{~h}$ and centrifuged at $121 \times g$ for $5 \mathrm{~min}$, and the supernatant was taken off. The procedure was repeated for $H$. bakeri but not for $C$. elegans, because $C$. elegans fragmented and lost their intact morphology. After the SDS wash, the worm pellet was washed again in PBS and centrifuged at $121 \times g$, and the last supernatant was taken off. The prepared worm cuticles were finally washed in $\mathrm{H}_{2} \mathrm{O}$ and stored in PBS at $-20{ }^{\circ} \mathrm{C}$ until they were used. $\beta$-Mercaptoethanol [35] was excluded in this procedure because it fragmented the cuticles, leading to loss of their intact cylindrical form.

\section{Preparation of CPs}

The two preparations of CPs used in this study were purified papain from papaya latex, purchased from Sigma-Aldrich UK (product no. P3125, $2 \times$ crystallised aqueous suspension) and papaya latex supernatant (PLS), prepared as described previously [26]. PLS contains a mixture of four papaya CPs: chymopapain, glycyl endopeptidase, caricain and papain (in order of abundance) [36]. On the day of use, the enzyme preparations were titrated for the molar concentration of active enzyme, using the irreversible CP inactivator L-trans-epoxysuccinyl-leucylamido(4-guanidino)butane (E64) (SigmaAldrich product no. E3132) [37, 38]. The active enzyme concentration was diluted with water to give a $4 \mu \mathrm{M}$ stock.

\section{Immunohistochemistry}

The C. elegans collagen gene $d p y-7$ knockout affects body shape (dumpy) [39, 40]. The DPY-7 cuticle collagen is predicted to have a carboxyl-terminal domain of 40 residues that is not shared with other $C$. elegans cuticle collagens [39]. The DPY-7-5a monoclonal antibody recognises specifically this "C"-terminal region of DPY-7 [39]. Using this antibody, we predicted that the presence or absence of a signal detection from cuticles with or without digestion by CP will indicate whether DPY-7 collagen is degraded or not by the CP. Additionally, DPY-7 immunohistochemistry can be used to monitor changes in cuticle structure during digestion of the cuticle components by a CP. For these experiments, we used wildtype (WT) C. elegans, and $d p y-7$ null strain MQ375. We used two slightly different methodologies; the first used a mini-fuge tube, and the second was performed in 24-well plates. We used the mini-fuge tube method because we suspected disturbance and possible breaking of worms during centrifugation, whereas in well plates, there was minimal or no disturbance of worms.

In the tube experiments, aliquots of washed WT or mutant dpy-7(qm63) C. elegans were thawed and rinsed with water by centrifugation at $121 \times g$ for $2 \mathrm{~min}$. The worms were partially reduced and made permeable with $1 \%$ dithiothreitol (DTT) or not [41], and were then incubated with $1 \mu \mathrm{M}$ papain or PLS, or papain or PLS $+1 \mathrm{mM}$ E64, at time points of 5, 10, 15 and $30 \mathrm{~min}$ at $37{ }^{\circ} \mathrm{C}$. Enzyme activity was then stopped with $1 \mathrm{mM}$ E64. The worms were washed with Tris-buffered saline $(\mathrm{pH} 7.0)$ with Tween 20 (TBST) by centrifugation at $121 \times g$ for $4 \mathrm{~min}$. The washing was repeated three more times to remove any trace of $\mathrm{CP}$, and non-specific binding sites were blocked for $4 \mathrm{~h}$ with $750 \mu \mathrm{l}$ of $5 \%$ skimmed milk in 
TBST. The worms were probed with $1 \mathrm{ml}$ of a 1:200 dilution of DPY-7 antibody for $4 \mathrm{~h}$ or overnight, followed by $1 \mathrm{ml}$ of a 1:500 dilution of goat anti-mouse IgG secondary antibody Alexa Fluor 488 conjugate (Thermo Fisher Scientific, UK) in the dark for $2 \mathrm{~h}$, and from there, samples were protected from light by wrapping in aluminium foil. The worm samples were centrifuged at $121 \times g$ for $2 \mathrm{~min}$. The washing was repeated twice. After washing, $10 \mu \mathrm{l}$ of worm suspension was pipetted onto a grease-free slide and mixed with mounting medium for fluorescence analysis (Vectashield H-1200) and protected with a coverslip.

In the 24-well plate method, all the conditions were the same as in the tube method except that the worms were not washed by centrifugation, but manually by pipetting the reagent with minimal disturbance to the worms which were not made permeable with $1 \%$ DTT. It is important to note that in all cases, the $\mathrm{CP}$ activity was totally eliminated by washing the samples in $1 \mathrm{mM}$ E64, followed by three washes in TBST for 4 min before application of antibody, eliminating the possibility of hydrolysis of the antibody by CP [42]. The worms were imaged with a DMI4000 B (Leica) inverted widefield fluorescence microscope, and the images were stored electronically.

\section{Scanning electron microscopy (SEM)}

Whole nematodes were used for this experiment. Approximately $30 \mathrm{C}$. elegans or $10 \mathrm{H}$. bakeri were added into each of four $1.5 \mathrm{ml} \mathrm{mini-fuge}$ tubes. The worms were incubated with $1 \mu \mathrm{M}$ (final concentration) of $\mathrm{CP}$ or $\mathrm{CP}+\mathrm{E} 64$ at a temperature of $37^{\circ} \mathrm{C}$ for 10,15 and $30 \mathrm{~min}$. At each time point, activity of CPs was stopped with $50 \mu \mathrm{l}$ of $1 \mathrm{mM}$ E64. The samples were then diluted with PBS and centrifuged at $121 \times g$ for $2 \mathrm{~min}$, and the supernatant was removed. This washing step was repeated three times to remove any trace of $\mathrm{CP}$. The samples were fixed in $2.5 \%$ glutaraldehyde in $0.1 \mathrm{M}$ phosphate buffer $(\mathrm{pH}$ 6.8) for $1 \mathrm{~h}$, before being washed for $20 \mathrm{~min}$ three times in PBS then fixed and stained with $1 \%$ osmium tetroxide in $0.1 \mathrm{M}$ phosphate buffer $\mathrm{pH} 6.8$ for $1 \mathrm{~h}$ at ambient temperature. The samples were washed three times in water and dehydrated by sequentially placing in $30 \%, 50 \%, 70 \%$, $90 \%$ and $100 \%$ ethanol. The specimens were then dried using a Polaron E3000 critical point dryer. The dried samples were mounted onto aluminium stubs using carbon discs. The stubs were gold sputter-coated (approximately $10 \mathrm{~nm}$ thick) using a Polaron E5100 SEM coating unit. All specimens were viewed and photographed using a JEOL JSM-840 scanning electron microscope at $23 \mathrm{kV}$, and the images were stored electronically.

Digestion of worm cuticles with CPs for proteomic analyses An aliquot ( 4500 C. elegans or 120 H. bakeri) of either prepared worm cuticles or whole worms was incubated in $1 \mu \mathrm{M}$ papain (final active concentration) or PLS (both activated with $4 \mathrm{mM} \mathrm{L}$-cysteine), or papain or PLS $+1 \mathrm{mM}$ E64 as the control, at $37^{\circ} \mathrm{C}$ for 10,15 and $30 \mathrm{~min}$. Twenty-five microlitres of the supernatant was collected at each time point and mixed with $20 \mu \mathrm{l}$ of $1 \mathrm{mM}$ E64 to stop further $\mathrm{CP}$ activity.

\section{Sodium dodecyl sulphate-polyacrylamide gel electrophoresis (SDS-PAGE) of CP digested worm supernatant}

The supernatant was mixed at a ratio of $1: 1$ with $2 \times$ sample buffer [4\% SDS, 20\% glycerol, 10\% DTT, 0.004\% bromophenol blue and $0.125 \mathrm{M}$ Tris $-\mathrm{HCl} \mathrm{pH} \mathrm{6.5]} \mathrm{and}$ boiled for $5 \mathrm{~min}$. Twenty microlitres of the boiled sample was loaded onto a $12 \%$ or $15 \%$ polyacrylamide 12 -well precast Mini Protean gel (Bio-Rad). Following electrophoresis at $120 \mathrm{~V}$, the gel was removed and fixed for $30 \mathrm{~min}$ in $5 \mathrm{ml}$ of $7 \%(\mathrm{v} / \mathrm{v})$ glacial acetic acid in $40 \%(\mathrm{v} / \mathrm{v})$ methanol. Later, the gel was stained with $150 \mathrm{ml}$ of $0.25 \%$ (w/v) colloidal Coomassie brilliant blue G concentrate in $50 \%$ methanol, $10 \%$ acetic acid and $40 \%$ water for at least $4 \mathrm{~h}$. After staining, the gel was rinsed with $10 \%$ acetic acid in $40 \%$ methanol for $1 \mathrm{~min}$. Rinsing was repeated, and the gel was de-stained overnight in $25 \%$ methanol on a shaker at ambient temperature. The next day the gel was washed, scanned using a Bio-Rad gel imager (Gel Doc $\mathrm{XR}^{+}$System) and recovered and fixed in $1 \%$ formic acid.

Peptide extraction and mass spectroscopy (LC/MS/MS)

In-gel tryptic digestion was a slight modification of the method described previously [43, 44] (see attached Additional file 1).

\section{Results}

Effects of CPs on the DPY-7 cuticle collagen of C. elegans

Figure 1 illustrates the immunochemical staining of the cuticles of $C$. elegans after incubation with $1 \mu \mathrm{M}$ papain. The DPY-7 collagen locates to parallel circumferential thread-like bands within the cuticle [32]. When WT C. elegans cuticles were incubated for $5 \mathrm{~min}$ in $1 \mu \mathrm{M}$ papain plus the CP inhibitor E64, a WT pattern of localisation of DPY-7 was observed (Fig. 1a) where the DPY-7 circumferential thread-like bands are intact and appear the same as for untreated specimens [32]. Staining of the C. elegans mutant strain $d p y-7$ (qm63) was performed as a negative control; this strain lacks the DPY-7 collagen and hence has no staining for DPY-7 (Fig. 1b). When WT C. elegans cuticles were incubated with $1 \mu \mathrm{M}$ papain for $5 \mathrm{~min}$, frequent areas of structural disruption of the circumferential band structures were observed (arrowed red in Fig. 1c-e). The areas of major disruption appeared to be relatively regularly spaced (between 4 and $6 \mu \mathrm{m}$ ), although many parts of the 


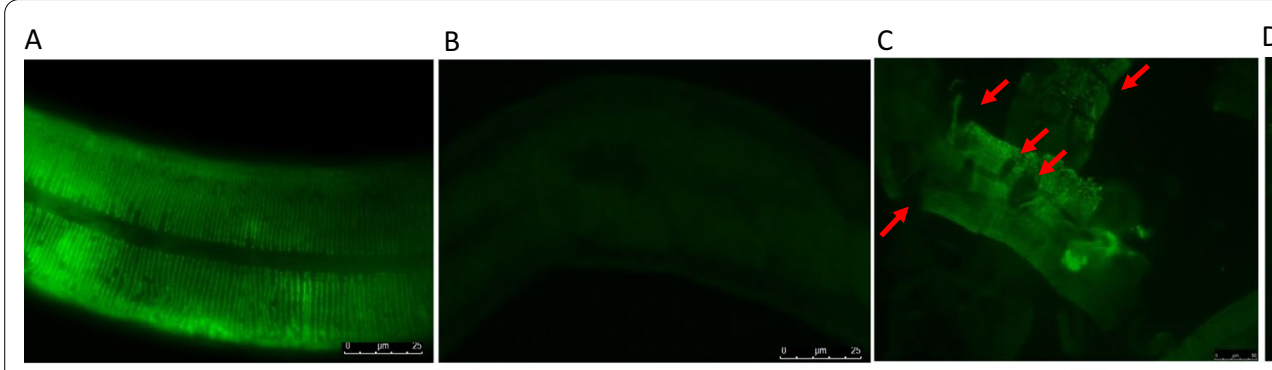

D

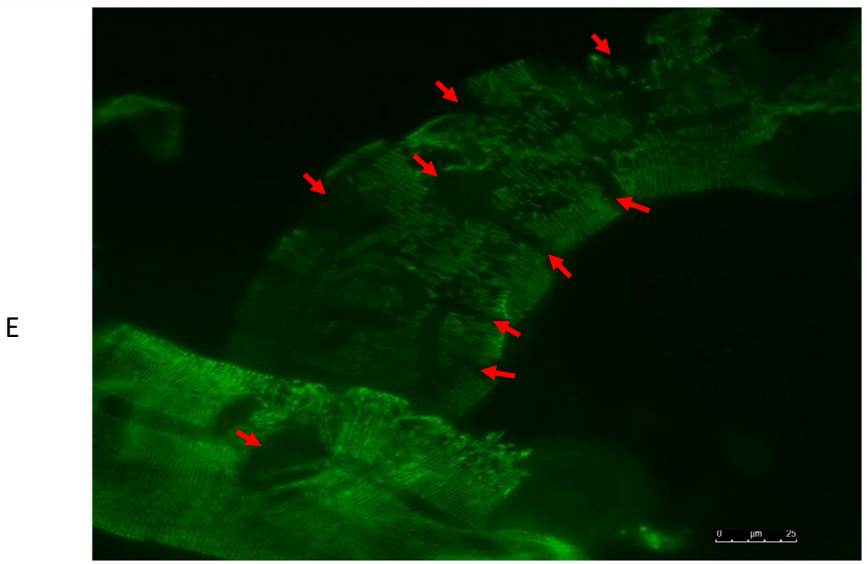

Fig. 1 Immunohistochemical investigation of the activities of papain on prepared cuticles of WT (Bristol N2) C. elegans. The worm cuticles were partially reduced with $1 \%$ DTT to increase permeability using the tube method then probed with the DPY-7 antibody. b Mutant $d p y-7$ (qm63) C. elegans used as the negative control. $\mathbf{c}$ and $\mathbf{d}$ Disruption of the WT cuticle after 5 min of incubation in $1 \mu \mathrm{M}$ papain. a A worm incubated in $1 \mu \mathrm{M}$ papain inactivated with E64 prior to incubation. e A magnified image showing the regular pattern of disruption (arrowed red) and progressive disappearance of DPY-7 at 5 min of incubation with $1 \mu \mathrm{M}$ papain, indicating the sequence of events leading to the collapse of the cuticle structure. $\operatorname{Bar}=25 \mu \mathrm{m}$

cuticles had also lost some circumferential bands. Both the alae and the entire cuticle components totally disappeared after 10 min of incubation. This suggests that DPY-7 is a target protein for papain. Figure 2 shows representative images following the immunochemical staining of the cuticles of WT C. elegans after worms were incubated with $1 \mu \mathrm{M}$ papain or papain $+\mathrm{E} 64$ in a 24-well plate without prior reduction in $1 \%$ DTT. The advantage of the plate method was that the worms were not disturbed by centrifugation, which allowed us to monitor progressively the activity of CP on the worms. The images presented here were of treated worms lying at the bottom of the wells, which were imaged without transferring to microscope slides. Worms incubated in papain for $5 \mathrm{~min}$ (Fig. 2b) were disrupted in the same regular pattern (red arrows) as was seen in worms prepared using the tube method (Fig. 1). This is in contrast with worms incubated in $1 \mu \mathrm{M}$ papain + E64 (Fig. 2a). In Fig. 2c, after $30 \mathrm{~min}$ in $1 \mu \mathrm{M}$ papain, the DPY-7 staining had mostly disappeared, and what was left had very little resolution (arrowed red). Some of the DPY-7 fluorescence remained until the cuticle was almost totally disrupted, indicating that this collagen species, or other proteins that are linked to it and holding it within the cuticle, may be a late target(s) for the CPs.

\section{Effects of CPs on C. elegans or H. bakeri visualised using scanning electron microscopy (SEM)}

In order to throw more light on the means by which CPs cause disruption of nematode cuticles, we went on to investigate by SEM the changes that occurred to adult $H$. bakeri cuticles, as well as C. elegans cuticles, including those of a knockout of a CP inhibitor (cpi-2) [30]. Whole WT or mutant cpi-2(ok1256) strains of C. elegans or $H$. bakeri were incubated with $\mathrm{CP}$ or $\mathrm{CP}+\mathrm{E} 64$ at time points of 10, 15 and $30 \mathrm{~min}$, then fixed and prepared for SEM. Figure 3 consists of electron micrographs of WT C. elegans incubated with $1 \mu \mathrm{M}$ papain with or without a molar excess of E64. The WT C. elegans incubated with papain +E64 appeared to be intact (Fig. 3a), with the alae of the worm (arrowed yellow) running longitudinally along the worm's body. This is in contrast with the worms incubated in $1 \mu \mathrm{M}$ papain (b-d) where the cuticles have varying degrees of damage. At $10 \mathrm{~min}$ of incubation in papain, the cuticle surfaces of the WT worms were wrinkled and disrupted (Fig. 3b). The disruption was 

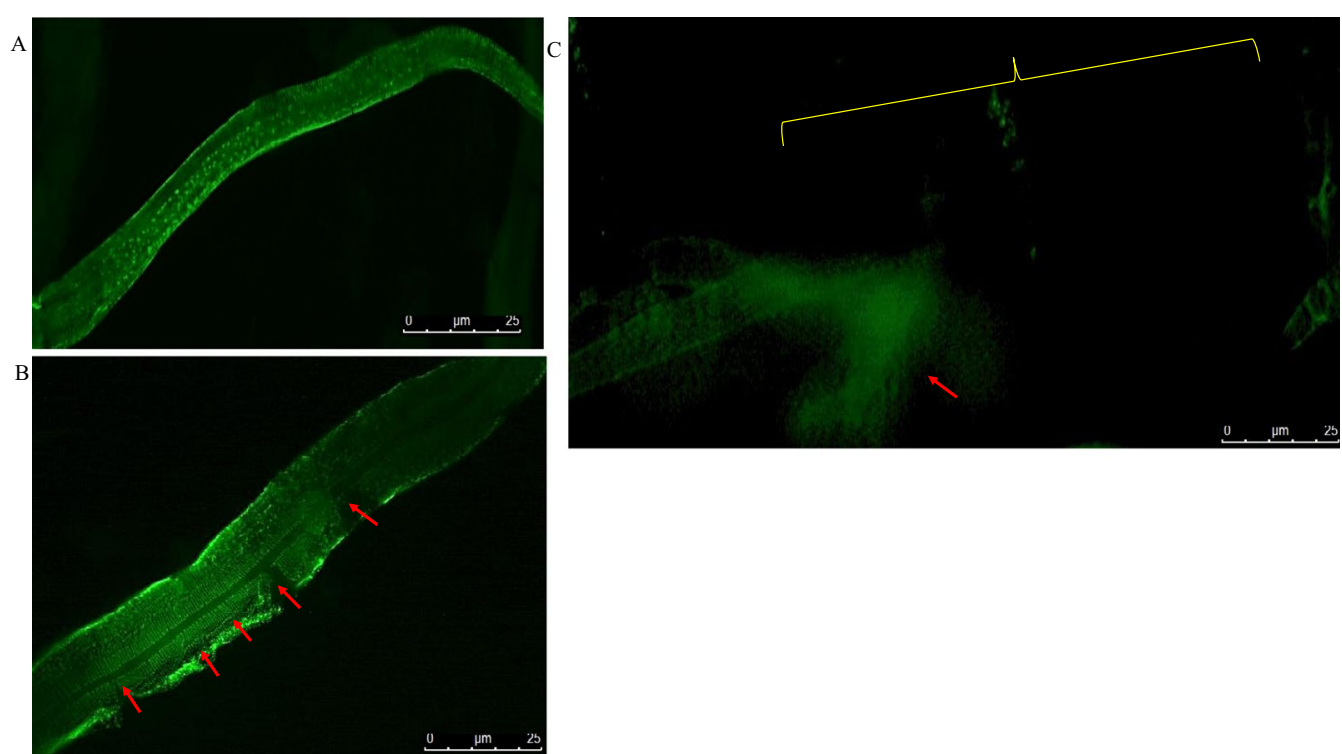

Fig. 2 Immunolocalisation of DPY-7 in WT C. elegans (Bristol N2) cuticles incubated with papain or papain + E64 in a 24-well plate. Whole intact worms were incubated with $1 \mu \mathrm{M}$ papain or papain + E64 without prior reduction in 1\% DTT. a A worm incubated with papain + E64 for 30 min. b Disruption of the C. elegans (Bristol N2 WT) cuticle (arrowed red) after 5 min incubation. c Total disappearance of the collagen stripes and loss of immunoreactivity (yellow brackets) after incubation for $30 \mathrm{~min}$. Bar $=25 \mu \mathrm{m}$
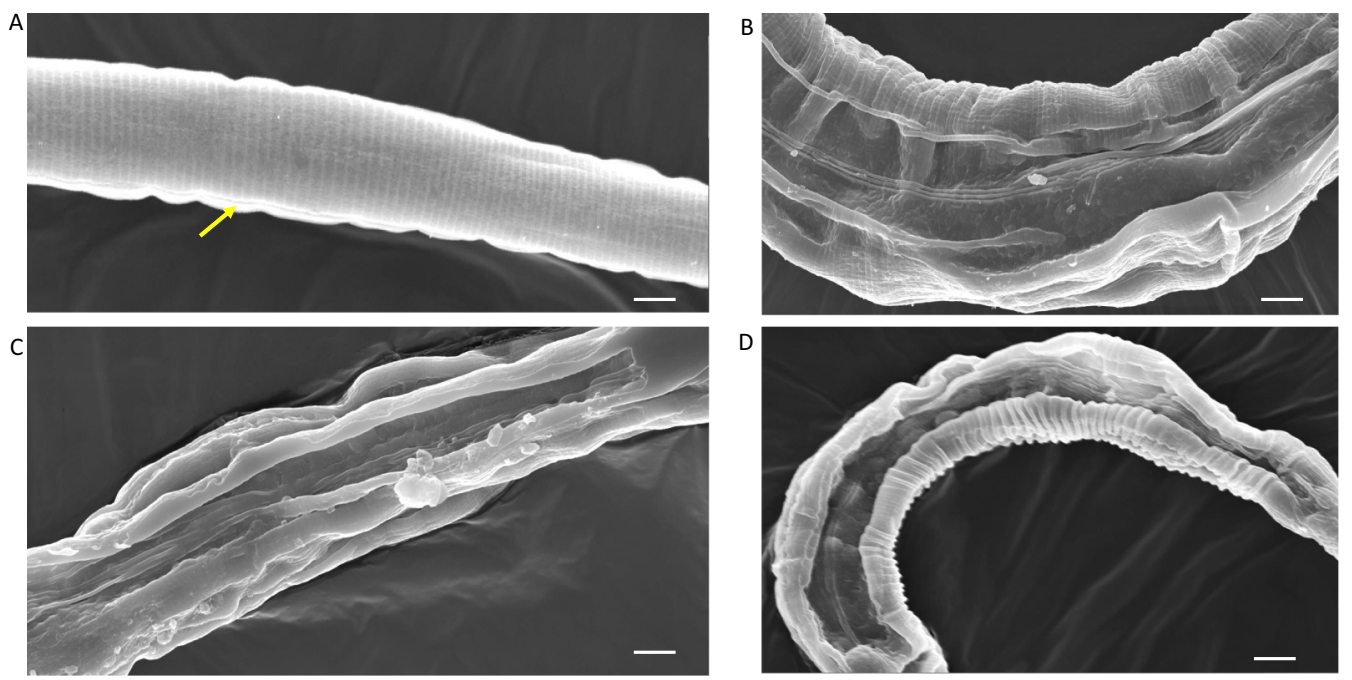

Fig. 3 SEM of WT (Bristol N2) C. elegans after incubation in $1 \mu M$ papain or papain + E64 at time points of 10, 15 and 30 min. a The worms were apparently intact and unaffected when incubated with papain + E64 for $30 \mathrm{~min}$, with the alae clearly visible (arrowed yellow). b After 10 min of incubation in papain, the cuticle appeared to be split longitudinally, which became more extensive at 15 min of incubation (c). By 30 min, the cuticle was split longitudinally, with a section of the cuticle totally destroyed or curled in on itself (d). Bar $=25 \mu \mathrm{m}$

apparently extensive at 15 min of incubation in papain (Fig. 3c), whereas at $30 \mathrm{~min}$, it appears that the worm has been split open longitudinally (Fig. 3d).

The electron micrographs of cpi-2(ok1256) mutant $C$. elegans incubated in $1 \mu \mathrm{M}$ papain or papain $+\mathrm{E} 64$ are shown in Figs. 4 and 5. Figure 4 illustrates the entire worms at low power, with the alae arrowed yellow in Fig. 4a. Figure 4b illustrates a worm after $5 \mathrm{~min}$ in papain, with wrinkling of the cuticle. After $15 \mathrm{~min}$, extensive wrinkling and blistering of the cuticle can be seen (Fig. 4c). At $30 \mathrm{~min}$, the cuticle has been split along the alae, with the cuticle on either side either folded over on 

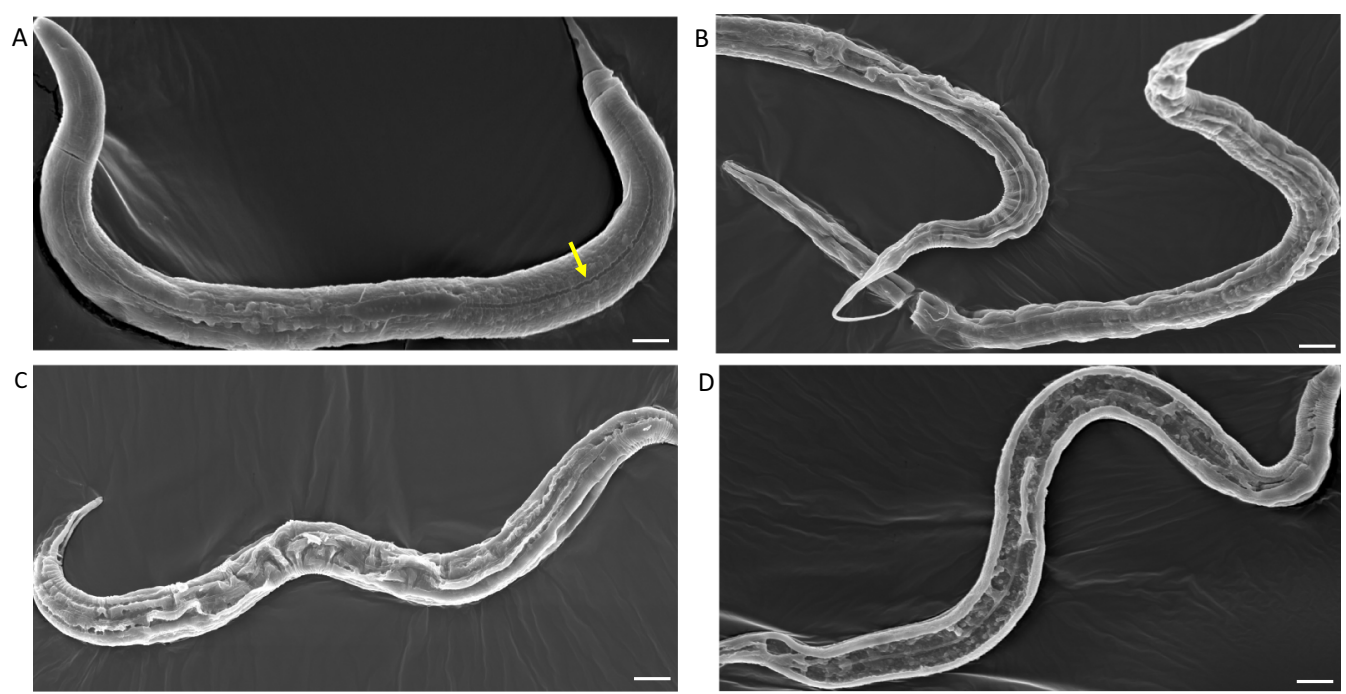

Fig. 4 SEM images of cpi-2(RB1207, ok1256) C. elegans incubated in papain or papain + E64. a cpi-2 (RB1207, ok1256) C. elegans worms incubated in papain + E64 for 30 min retained their intact status with the alae (arrowed yellow) visibly running longitudinally along the worm. $\mathbf{b}$ At $10 \mathrm{~min}$ of incubation in papain, cpi-2(RB1207, ok1256) C. elegans showed wrinkling of the cuticles. c By 15 min, extensive blistering of the cuticles was apparent. At $30 \mathrm{~min}$, most of the cuticle was lost or split along the alae, exposing the internal cavity (d). Bar $=50 \mu \mathrm{m}$
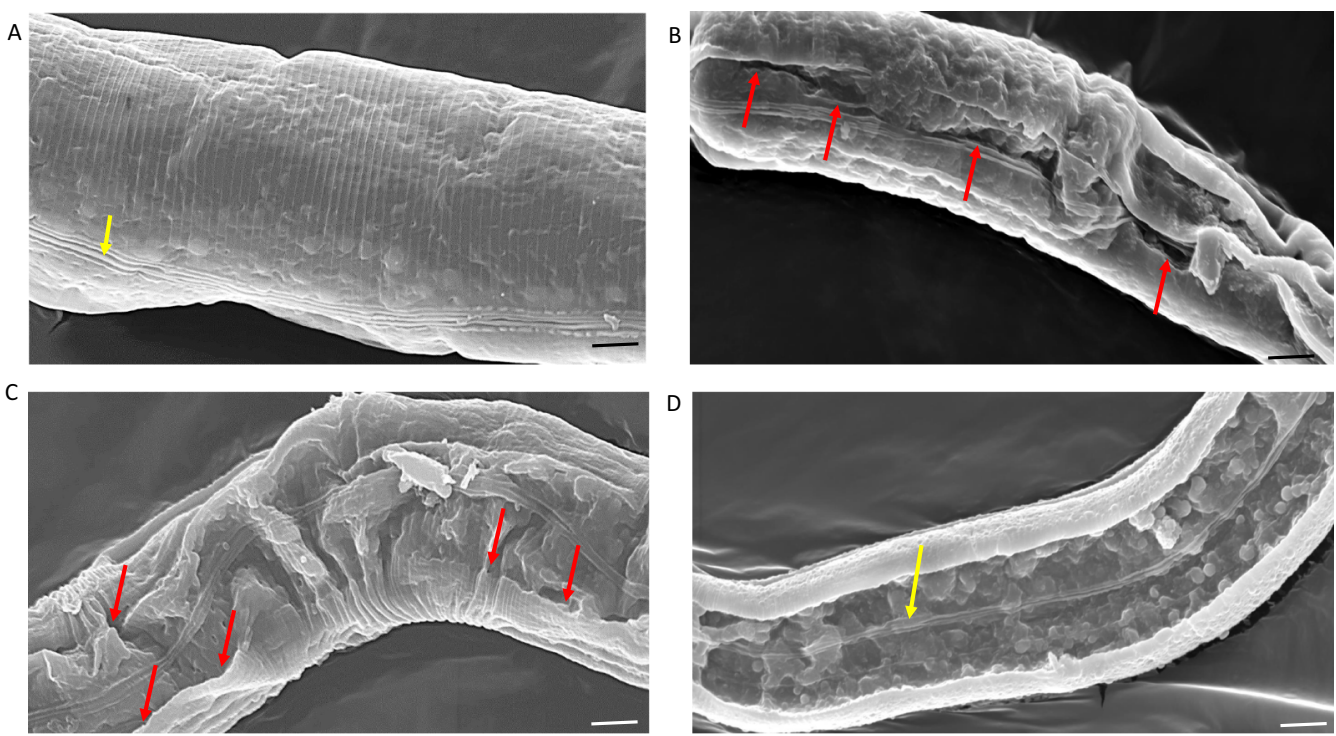

Fig. 5 SEM images of cpi-2(RB1207, ok1256) C. elegans incubated in papain or papain + E64. a Worms incubated for 30 min in papain + E64 clearly showed the delicate intact structure of the cuticle, with the alae being clearly visible (yellow arrow). b By contrast, after 10 min of incubation, worms incubated in papain showed tearing or were split longitudinally along a line very close to the alae (arrowed red). c At 15 min, the papain-induced cuticle disruption probably caused the cuticles to detach from the rest of the body in what appeared to be sheets of cuticle (arrowed red). $\mathbf{d}$ After 30 min of incubation, the cuticle was often split longitudinally, in some cases, with the alae on the opposite side of the worm still intact (yellow arrow). Bar $=10 \mu \mathrm{m}$

itself or missing completely (Fig. 4d). At higher magnification, the cpi-2(ok1256) mutant C. elegans were damaged by papain (Fig. $5 \mathrm{~b}-\mathrm{d}$ ) when contrasted to worms incubated in papain $+\mathrm{E} 64$, where the cuticle, including the alae (yellow arrow), appears to be intact, even after 30 min of incubation (Fig. 5a). At 10 min of incubation, worms incubated in papain showed tears longitudinally along the alae (arrowed red, Fig. 5b). The papain-induced 
tearing may have caused the cuticles to detach from the rest of the body by $15 \mathrm{~min}$ in what appear to be sheets of cuticle (arrowed red in Fig. 5c). A ribbon-like structure (arrowed yellow) appears to be the alae still intact on the opposite side of the worm, with the entire inner contents of the nematode having been lost by $30 \mathrm{~min}$ of incubation with papain (Fig. 5d).

Compared to C. elegans, when incubated with $1 \mu \mathrm{M}$ papain, $H$. bakeri showed greater susceptibility to damage by $\mathrm{CP}$ at all the incubation times (Fig. 6). At $10 \mathrm{~min}$ of incubation, the worms already appeared totally digested with only a fragment of the gut being anatomically discernible (Fig. 6b). The worms were totally digested at 15 and $30 \mathrm{~min}$ of incubation with only the insoluble precipitates left after incubation (Fig. 6c and d). The damage to H. bakeri was caused by CP action as worms incubated in papain + E64 were not affected but retained their intact status (Fig. 6a).

\section{Target proteins for CPs on intact $H$. bakeri or prepared $H$. bakeri cuticles, or whole C. elegans}

Nematode cuticles are substrates for CPs, and some cleaved products of hydrolysis are likely to be soluble. We analysed soluble products from prepared cuticles or whole $H$. bakeri incubated in $\mathrm{CP}$ or $\mathrm{CP}+\mathrm{E} 64$, with SDS-PAGE. Bands that were unique in the papain digests or in the papain + E64 incubations were selected for in-gel trypsin digestion in conjunction with mass spectrometry analysis to identify the corresponding proteins (Additional file 1: Tables S1 and S2). Cuticle globin ( $g i / 8569651)$, required for respiration by the nematode $[45,46]$, was one of the proteins identified using papain
(Additional file 1: Table S1). In addition, a single peptide identified the structural protein CUT-19. However, as only a single peptide was identified, further validation is required. Cuticlins are major and important structural components of the nematode cuticle, and their hydrolysis is expected to lead to loss of integrity of the entire cuticle structure, weakening it sufficiently to enable its rupture through the high hydrostatic pressure within the pseudoceolomic cavity.

Caenorhabditis elegans or washed C. elegans cuticles were incubated with papain or papain + E64 (Additional file 1: Tables S3 and S4). Similarly, whole C. elegans or washed C. elegans cuticles were also incubated with PLS and PLS plus E64 (Additional file 1: Table S5). Following SDS-PAGE, the unique bands were selected for in-gel trypsin digestion in conjunction with mass spectrometry analysis to identify the corresponding proteins. Of particular interest was the identification of an important cuticle structural protein, COL-87. However, as the protein was identified by a single peptide, further validation is required.

\section{Discussion}

In view of the threat of nematode resistance, our attention is on the development of drugs with multiple modes of action, i.e. with more than one target molecule and reduced likelihood of development of resistance. Focus has been on CPs and earlier reports of their effectiveness as anthelmintics [26-28, 47]. Although CPs attack and destroy nematode cuticles, the molecular target(s) and possible sites of activity on the structural proteins that constitute the cuticle have not been investigated.
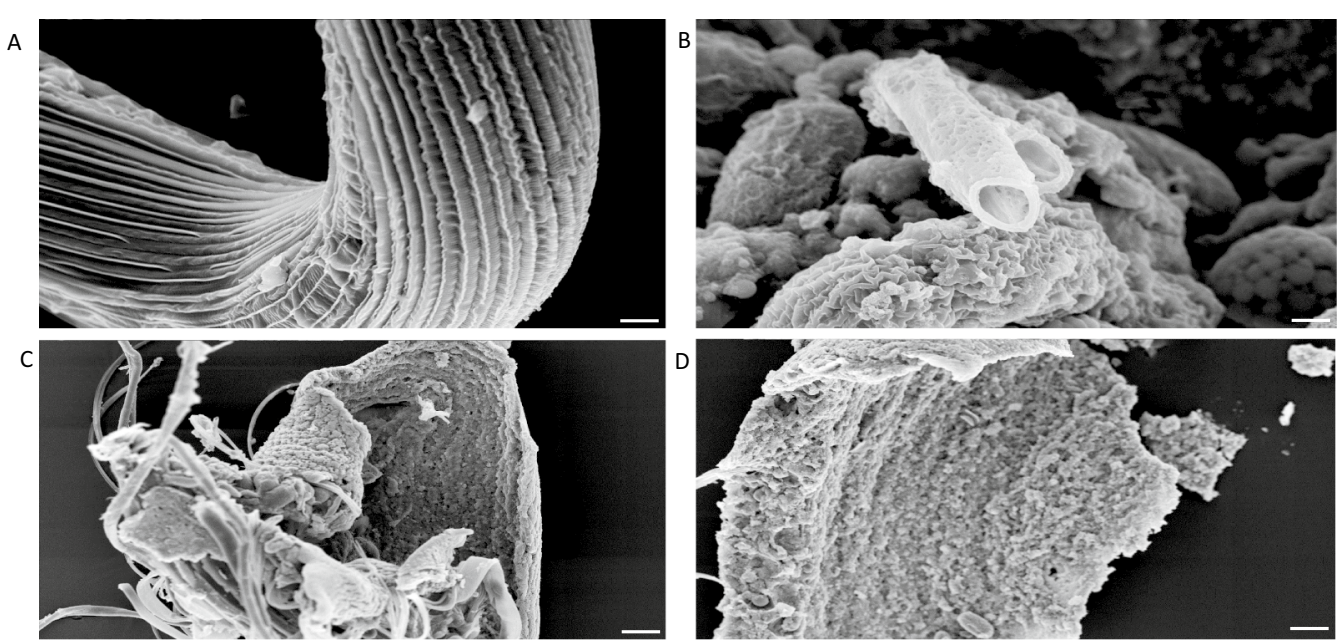

Fig. 6 SEM of H. bakeri incubated in papain or papain + E64. H. bakeri incubated in papain + E64 for 30 min were intact and appeared undamaged (a), whereas worms incubated in $1 \mu \mathrm{M}$ papain for 10 min or longer showed rapid and extensive digestion and were no longer recognisable (b 10, $\mathbf{c}$ $15 \mathrm{~min}$ ). After $30 \mathrm{~min}$ of incubation, all that remained were sheets of insoluble material (d). $\mathrm{Bar}=25 \mu \mathrm{m}$ 
For an anthelmintic based on CPs to be used on a large scale at an economic price, it is likely that a preparation such as PLS will be employed. This is a mixture of four closely related CPs, one of which is papain [36]. In order to simplify the interpretation of our data, particularly those using the proteomic approach, we decided to employ purified papain in our experiments alongside PLS. The effect of papain on the nematode cuticle is superficially similar to that of PLS, but it is unlikely that the two preparations will have identical effects.

DPY-7 collagen is a target for CPs on the cuticle of $C$. elegans. Our study found that the loss of DPY-7 immunoreactivity in C. elegans is time-dependent and that hydrolysis of DPY-7 or its disappearance by other means probably began before $5 \mathrm{~min}$ at a $1 \mu \mathrm{M}$ concentration of CPs, whereas total loss of DPY-7 immunoreactivity appeared to take place when the worms were incubated longer in papain for up to $30 \mathrm{~min}$. The time course of the loss of DPY-7 immunoreactivity on C. elegans was slow enough to allow us to use it to visualise anatomical disruption of the entire nematode cuticle by $\mathrm{CP}$. The nematode cuticle is a multi-layered structure with about $80 \%$ of its protein as collagen [40]. DPY-7, DPY-2, DPY-3, DPY-8 and DPY-10 are obligate partners and are necessary in the formation of the thin thread-like structures needed for the genesis and maintenance of the annular furrows of C. elegans cuticles [39]. Therefore, loss of DPY-7 immunoreactivity by CP would suggest the destruction of the framework of the cuticle leading to loss of cuticular structure. This could be due to the hydrolysis by $\mathrm{CP}$ of any one or more of these components, or of others that have not yet been identified, resulting in collapse of the whole architecture of the cuticle, possibly seen as wrinkling on the surface as is usually associated with $\mathrm{CP}$ attack on the cuticles of parasitic nematodes [28]. As the time of incubation was increased, more of the DPY-7 and probably the other cuticle collagen proteins were hydrolysed, making the cuticle weaker, the physical result of which is the loss of integrity of the cuticle as seen with SEM and loss of DPY-7 immunoreactivity observed in immunohistochemical imaging of C. elegans incubated in CP. The disruption and digestion of the H. bakeri or $C$. elegans cuticles by CPs was a time-dependent but quite rapid process, producing severe damage to the cuticles. This suggests that there are many targets for CPs on nematode cuticles, most of which remained unidentified.

SEM demonstrated that dead H. bakeri are more susceptible to CP attack than dead C. elegans. An earlier report [30] indicated that the dose of $\mathrm{CP}$ that kills a parasitic nematode was unable to cause the death of wild type C. elegans. C. elegans possess CP inhibitors, presumably to protect against exogenous CPs in their external environments containing bacteria, fungi and decaying plant material [30]. With H. bakeri, Stepek et al. [48] observed cuticular damage after $15 \mathrm{~min}$ of incubating living $H$. bakeri in $200 \mu \mathrm{M}$ papain, a 100 -fold higher concentration than was used in this study. The difference in the amount of CP needed to cause cuticular damage to living and dead $H$. bakeri might be related to the presence or absence of cystatin secretions. H. bakeri cystatin(s) is involved in immunoregulation [17] and is presumed to be a secreted protein, so could influence $\mathrm{CP}$ activity if the animal is alive. The influence of cystatins in dead worms might be lessened by the inability to release cystatins from a store elsewhere in the worm and mobilised to the cuticles as may occur in the living nematode, as seems to be the case in live C. elegans [30]. As components of secretory products of parasitic nematodes, cystatins may be deposited in the cuticles [17, 48, 49]. In the situation where there are cystatins within the cuticles, our cuticle preparation would most likely have removed any cystatins, making the cuticles more susceptible to the action of CPs.

A cuticle-related protein, extracellular cuticle globin, was identified from $H$. bakeri samples incubated with CPs. Its absence in the cuticles incubated in papain + E64 indicates that it was released by papain. This extracellular cuticle globin has high-affinity oxygen binding and is required by the parasitic nematodes to obtain oxygen in their near anaerobic environment within the host gut [50]. Disruption of cuticle globin by papain would disengage the mechanism through which the worm obtains oxygen from its host. We therefore conclude that CPs are able to disrupt the mechanism of oxygen uptake from the host, another potential killing method.

Nematode cuticle structural proteins are held together by covalent tyrosine cross-links [51]. The failure to identify many structural proteins is likely to be due to the inability of MS software to identify peptides containing tyrosine cross-links. The presence of the cross-links as well as the likelihood that many of the cross-links are formed between different cuticular collagen and cuticlin gene products will make the resulting structure impossible for the software to recognise. The only peptides that could be recognised would be those that do not contain tyrosine cross-links and are the product of a single gene. In C. elegans, about 160 and at least 8 functionally defined genes encode for cuticle collagens and cuticlins, respectively $[40,52]$, which are all likely to be substrates for the formation of tyrosine-based cross-links [15, 53].

We identified a single peptide from each of two cuticle structural proteins, COL-87 and CUT-19, in digests of $H$. bakeri and C. elegans, which may suggest that, along with DPY-7, these structural proteins may be cuticular targets for CPs. No examples of structural cuticle components were found in any of our control 
samples where the action of the CPs was blocked by the irreversible CP inactivator E64. Other proteomic analyses of nematodes have failed to identify significant numbers of peptides from cuticle proteins [42, 46], presumably for the reasons outlined above. For these reasons, we consider COL-87 and CUT-19, along with DPY-7, to be possible CP targets in the cuticle.

The pattern of activity of CPs on nematodes is evidently novel and involves the targeting of a number of different gene products, making resistance of nematodes to anthelmintics derived from CPs difficult to achieve. We therefore suggest that CPs are good candidates for an anthelmintic with a completely novel mode of action from those attributed to other anthelmintics, and that development of resistance against CPs by nematodes will be slow as it will probably require simultaneous mutations of a number of different genes encoding collagens, cuticlins, and possibly other essential components of the nematode cuticle.

\begin{abstract}
Abbreviations
CP: Cysteine proteinase; DTT: Dithiothreitol; E64: L-trans-epoxysuccinylleucylamido(4-guanidino)butane; HBSS: Hank's balanced salt solution; LC/ MS/MS: Liquid chromatography-tandem mass spectrometry; PBS: Phosphatebuffered isotonic saline; PLS: Papaya latex supernatant; SEM: Scanning electron microscopy; SDS-PAGE: Sodium dodecyl sulphate-polyacrylamide gel electrophoresis; TBST:Tris-buffered saline with Tween-20;WT:Wild type.
\end{abstract}

\section{Supplementary Information}

The online version contains supplementary material available at https://doi. org/10.1186/s13071-021-04800-8.

Additional file 1. Contains additional methodology and tabulated results.

\section{Acknowledgements}

We are grateful to Alison Nwokeoji for assisting with proteomic analysis and Fiona Wright for general laboratory assistance.

\section{Authors' contributions}

$D J B, V S N, M D, I D$ and IJ were involved in the design of various parts of this study. VSN carried out the experiments. TW and OD cultured and maintained C. elegans and aided with the proteomic and antibody experiments. ID performed SEM. AL and JB maintained and infected mice with $H$. bakeri. VSN and DJB wrote the manuscript. All authors read and approved the final manuscript.

\section{Funding}

External funding was provided by the Tertiary Education Trust Fund (TETFUND), through Enugu State University of Science and Technology, Enugu, Federal Republic of Nigeria.

\section{Declarations}

\section{Ethics approval and consent to participate}

Mice were maintained and treated as covered by Home Office

Licence 40/3138. No human material was used in the course of this work.

\section{Consent for publication}

All authors consented to publication.

\section{Competing interests}

There are no competing interests.

\section{Author details}

${ }^{1}$ Department of Infection, Immunity and Cardiovascular Disease, The University of Sheffield Medical School, Beech Hill Road, Sheffield S10 2RX, UK. ${ }^{2}$ Department of Applied Biology and Biotechnology, Enugu State University of Science and Technology, Enugu 1660, PMB, Nigeria. ${ }^{3}$ Department of Biosciences and Chemistry, Sheffield Hallam University, Sheffield S1 1WB, UK. ${ }^{4}$ School of Life Sciences, University of Nottingham, University Park, Nottingham NG7 2RD, UK. ${ }^{5}$ Department of Chemical and Biological Engineering, ChELSI Institute, The University of Sheffield, Sheffield S1 3JD, UK. ${ }^{6}$ Department of Life Sciences and Biomolecular Sciences, University of Glasgow, Glasgow, UK.

Received: 5 April 2021 Accepted: 24 May 2021

Published online: 05 June 2021

\section{References}

1. de Silva NR. Impact of mass chemotherapy on the morbidity due to soiltransmitted nematodes. Acta Trop. 2003;86:197-214.

2. Gyapong M, Nartey A, Oti E, Page S. The social and economic impact of neglected tropical diseases in sub-Saharan Africa. In: Gyapong J, Boatin B, editors. Neglected Tropical Diseases - Sub-Saharan Africa. Cham: Springer International Publishing; 2016. p. 349-65.

3. Roeber F, Jex AR, Gasser RB. Impact of gastrointestinal parasitic nematodes of sheep, and the role of advanced molecular tools for exploring epidemiology and drug resistance - an Australian perspective. Parasit Vectors. 2013:6:153.

4. Nicol JM, Turner SJ, Coyne DL, Den Nijs L, Hockland S, Maafi ZT: Current nematode threats to world agriculture. In: Genomics and Molecular Genetics of Plant-nematode Interactions: Springer; 2011: 21-43.

5. Albonico M, Rinaldi L, Sciascia S, Morgoglione ME, Piemonte M, Maurelli MP, Musella V, Utzinger J, Ali SM, Ame SM, et al. Comparison of three copromicroscopic methods to assess albendazole efficacy against soil-transmitted helminth infections in school-aged children on Pemba Island. Trans R Soc Trop Med Hyg. 2013;107:493-501.

6. Martin RJ. Modes of action of anthelmintic drugs. Vet J. 1997;154:11-34.

7. Geerts S, Gryseels B. Drug resistance in human helminths: current situation and lessons from livestock. Clin Microbiol Rev. 2000;13:202-22.

8. Geerts S, Gryseels B. Anthelmintic resistance in human helminths: a review. Trop Med Int Health. 2001;6:915-21.

9. Shalaby HA. Anthelmintics resistance; how to overcome it? Iranian J Parasitol. 2013:8:18-32.

10. Geurden T, Hoste H, Jacquiet P, Traversa D, Sotiraki S, di Regalbono AF, Tzanidakis N, Kostopoulou D, Gaillac C, Privat S, et al. Anthelmintic resistance and multidrug resistance in sheep gastrointestinal nematodes in France Greece and Italy. Vet Parasitol. 2014;201:59-66.

11. Kaplan RM. Drug resistance in nematodes of veterinary importance: a status report. Trends Parasitol. 2004;20:477-81.

12. Vercruysse J, Levecke B, Prichard R. Human soil-transmitted helminths: implications of mass drug administration. Curr Opin Infect Dis. 2012;25:703-8.

13. Fetterer RH, Rhoads ML, Urban JF Jr. Synthesis of tyrosine-derived crosslinks in Ascaris suum cuticular proteins. J Parasitol. 1993;79:160-6.

14. Edens WA, Sharling L, Cheng G, Shapira R, Kinkade JM, Lee T, Edens HA, Tang X, Sullards C, Flaherty DB, et al. Tyrosine cross-linking of extracellular matrix is catalyzed by Duox, a multi-domain oxidase/peroxidase with homology to the phagocyte oxidase subunit gp91 phox. J Cell Biol. 2001;154:879-91.

15. Page AP, Stepek G, Winter AD, Pertab D. Enzymology of the nematode cuticle: a potential drug target? Int J Parasitol: Drugs Drug Res. 2014;4:133-41.

16. Hawley JH, Martzen MR, Peanasky RJ. Proteinase inhibitors in Ascarida. Parasitol Today. 1994;10:308-13.

17. Hewitson JP, Grainger JR, Maizels RM. Helminth immune-regulation: the role of parasite secreted proteins in modulating host immunity. Mol Biochem Parasitol. 2009;167:1-11. 
18. Molehin AJ, Gobert GN, McManus DP. Serine protease inhibitors of parasitic helminths. Parasitology. 2012;139:681-95.

19. Waller PJ, Bernes G, Thamsborg SM, Sukura A, Richter SH, Ingebrigtsen K Höglund: Plants as de-worming agents of livestock in the Nordic Countries: historical perspective, popular beliefs and prospects for the future. Acta Vet Scand. 2001;42:31-44.

20. Berger J, Asenjo CP. Anthelmintic activity of fresh pineapple juice. Science. 1939;90:299-300.

21. Berger J, Asenjo CP. Anthelmintic activity of crystalline papain. Science. 1940;91:387-8.

22. Satrija F, Nansen P, Bjorn $H$, Murtini $S$, He S. Effect of papaya latex against Ascaris suum in naturally infected pigs. J Helminthol. 1994;68:343-6.

23. Rawlings ND, Barrett AJ, Finn R. Twenty years of the MEROPS database of proteolytic enzymes, their substrates and inhibitors. Nucleic Acids Res. 2016;44:D343-50

24. Stepek G, Buttle DJ, Duce IR, Behnke JM. Human gastrointestinal nematode infections: are new control methods required? Int J Exp Pathol. 2006;87:325-41.

25. Behnke JM, Buttle DJ, Stepek G, Lowe A, Duce IR. Developing novel anthelmintics from plant cysteine proteinases. Parasit Vectors. 2008;1:29.

26. Buttle DJ, Behnke JM, Bartley Y, Elsheikha HM, Bartley DJ, Garnett MC, Donnan AA, Jackson F, Lowe A, Duce IR. Oral dosing with papaya latex is an effective anthelmintic treatment for sheep infected with Haemonchus contortus. Parasit Vectors. 2011:4:36.

27. Levecke B, Buttle DJ, Behnke JM, Duce IR, Vercruysse J. Cysteine proteinases from papaya (Carica papaya) in the treatment of experimental Trichuris suis infection in pigs: two randomized controlled trials. Parasit Vectors. 2014;7:255.

28. Stepek G, Lowe A, Buttle DJ, Duce IR, Behnke JM. The anthelmintic efficacy of plant-derived cysteine proteinases against the rodent gastrointestinal nematode, Heligmosomoides polygyrus, in vivo. Parasitology. 2007;134:1409-19.

29. Stepek G, Curtis RH, Kerry BR, Shewry PR, Clark SJ, Lowe A, Duce IR, Buttle $D J$, Behnke JM. Nematicidal effects of cysteine proteinases against sedentary plant parasitic nematodes. Parasitology. 2007;134:1831-1183.

30. Phiri AM, De Pomerai D, Buttle DJ, Behnke JM. Developing a rapid throughput screen for detection of nematicidal activity of plant cysteine proteinases: the role of Caenorhabditis elegans cystatins. Parasitology. 2014;141:164-80

31. Guiliano DB, Hong X, McKerrow JH, Blaxter ML, Oksov Y, Liu J, Ghedin E, Lustigman S. A gene family of cathepsin L-like proteases of filarial nematodes are associated with larval molting and cuticle and eggshell remodeling. Mol Biochem Parasitol. 2004;136:227-42.

32. Thein MC, McCormack G, Winter AD, Johnstone IL, Shoemaker CB, Page AP. Caenorhabditis elegans exoskeleton collagen COL-19: An adult-specific marker for collagen modification and assembly, and the analysis of organismal morphology. Dev Dyn. 2003;226:523-39.

33. Luoga W, Mansur F, Stepek G, Lowe A, Duce IR, Buttle DJ, Behnke JM. Host genetic influences on the anthelmintic efficacy of papaya-derived cysteine proteinases in mice. Parasitology. 2015;142:989-98.

34. Behnke JM, Harris PD. Heligmosomoides bakeri: a new name for an old worm? Trends Parasitol. 2010;26:524-9.

35. Cox GN, Kusch M, Edgar RS. Cuticle of Caenorhabditis elegans: its isolation and partial characterization. J Cell Biol. 1981;90:7-17.

36. Buttle DJ, Dando PM, Coe PF, Sharp SL, Shepherd ST, Barrett AJ. The preparation of fully active chymopapain free of contaminating proteinases. Biol Chem Hoppe-Seyler. 1990;371:1083-8.
37. Zucker S, Buttle DJ, Nicklin MJ, Barrett AJ. The proteolytic activities of chymopapain, papain, and papaya proteinase III. Biochim Biophys Acta. 1985;828:196-204.

38. Luoga W, Mansur F, Buttle DJ, Duce IR, Garnett MC, Behnke JM. The anthelmintic efficacy of papaya latex in a rodent-nematode model is not dependent on fasting before treatment. J Helminthol. 2012;86:311-6.

39. McMahon L, Muriel JM, Roberts B, Quinn M, Johnstone IL. Two Sets of Interacting Collagens Form Functionally Distinct Substructures within a Caenorhabditis elegans Extracellular Matrix. Mol Biol Cell. 2003;14:1366-78.

40. Page AP, Johnstone IL. The cuticle. WormBook. 2007;19:1-15.

41. Thein MC, Winter AD, Stepek G, McCormack G, Stapleton G, Johnstone IL, Page AP. Combined Extracellular Matrix Cross-linking Activity of the Peroxidase MLT-7 and the Dual Oxidase BLI-547 3 Is Critical for Post-Embryonic Viability in Caenorhabditis elegans. J Biol Chem. 2009;284:17549-63.

42. Andrew SM, Titus JA: Purification of immunoglobulin G. Curr Protoc Immunol 2001, 2

43. Van Steendam K, De Ceuleneer M, Dhaenens M, Van Hoofstat D, Deforce D. Mass spectrometry-based proteomics as a tool to identify biological matrices in forensic science. Int J Leg Med. 2013;127:287-98.

44. Wang T, van Steendam K, Dhaenens M, Vlaminck J, Deforce D, Jex AR, Gasser RB, Geldhof P. Proteomic analysis of the excretory-secretory products from larval stages of Ascaris suum reveals high abundance of glycosyl hydrolases. PLoS Neg Trop Dis. 2013;7:e2467.

45. Barrett J, Brophy PM. Ascaris haemoglobin: new tricks for an old protein. Parasitol Today. 2000;16:90-1.

46. Blaxter ML. Nemoglobins: divergent nematode globins. Parasitol Today. 1993:9:353-60

47. Stepek G, Lowe A, Buttle DJ, Duce IR, Behnke JM. In vitro and in vivo anthelmintic efficacy of plant cysteine proteinases against the rodent gastrointestinal nematode Trichuris muris. Parasitology. 2006;132:681-9.

48. Stepek G, Buttle DJ, Duce IR, Lowe A, Behnke JM. Assessment of the anthelmintic effect of natural plant cysteine proteinases against the gastrointestinal nematode, Heligmosomoides polygyrus, in vitro. Parasitology. 2005;130:203-11.

49. Hewitson JP, Harcus Y, Murray J, van Agtmaal M, Filbey KJ, Grainger JR, Bridgett S, Blaxter ML, Ashton PD, Ashford DA, et al. Proteomic analysis of secretory products from the model gastrointestinal nematode Heligmosomoides polygyrus reveals dominance of Venom Allergen-Like (VAL) proteins. J Proteom. 2011;74:1573-94.

50. Daub J, Loukas A, Pritchard DI, Blaxter M. A survey of genes expressed in adults of the human hookworm Necator americanus. Parasitology. 2000;120:171-84.

51. The cuticle. http://www.wormbook.org.

52. Cox GN, Kusch M, Denevi K, Edgar RS. Temporal regulation of cuticle synthesis during development of Caenorhabditis elegans. Dev Biol. 1981;84:277-85.

53. Fetterer RH, Hill DE, Urban JF Jr. The cuticular biology in developmental stages of Ascaris suum. Acta Trop. 1990;47:289-95.

\section{Publisher's Note}

Springer Nature remains neutral with regard to jurisdictional claims in published maps and institutional affiliations.

Ready to submit your research? Choose BMC and benefit from:

- fast, convenient online submission

- thorough peer review by experienced researchers in your field

- rapid publication on acceptance

- support for research data, including large and complex data types

- gold Open Access which fosters wider collaboration and increased citations

- maximum visibility for your research: over $100 \mathrm{M}$ website views per year

At BMC, research is always in progress.

Learn more biomedcentral.com/submissions 